\title{
Ultraviolet Protection, Flame Retardancy and Antibacterial Properties of Treated Polyester Fabric Using Plasma-Nano Technology
}

\author{
Wafaa M. Raslan', Usama S. Rashed ${ }^{2}$, Hanan El-Sayad', Azza A. El-Halwagy ${ }^{1}$ \\ ${ }^{1}$ Textile Research Division, National Research Centre, Cairo, Egypt; ${ }^{2}$ Physics Department, Faculty of Science, Al-Azhar University, \\ Cairo, Egypt. \\ Email: wafaa_raslan@hotmail.com,wafaa_raslan@yahoo.com
}

Received March 11 ${ }^{\text {th }}, 2011$; revised June 21 ${ }^{\text {st }}, 2011$; accepted June $27^{\text {th }}, 2011$.

\begin{abstract}
Nanotechnology provides the ability to engineer the properties of materials. The possibility of using dielectric barrier discharge $(D B D)$ air plasma treatment for fibre surface activation to facilitate deposition of aluminum oxide $\left(\mathrm{Al}_{2} \mathrm{O}_{3}\right)$, nano-silver $(\mathrm{Ag})$ and nano-titanium dioxide $\left(\mathrm{TiO}_{2}\right)$ onto polyester fabric is investigated. It is aimed to study the possibility of engineering the multifunctional of polyester fabric. The treated fabric is evaluated through measuring the whiteness index (WI), wettability, surface roughness, surface morphology, flame retardancy, ultraviolet protection factor $(U P F)$, thermo-gravimetric analysis (TGA), antibacterial activity, mechanical properties, and coloration behavior as well as fastness properties. Scan electron microscopy (SEM) and transmission electron microscopy (TEM) graphs show deposition of $\mathrm{Al}_{2} \mathrm{O}_{3}$ and nano particles (NPs) of $\mathrm{TiO}_{2}$ and $\mathrm{Ag}$ onto the fibre after washing several times. Air plasma$\mathrm{Al}_{2} \mathrm{O}_{3}$ treatment improves the flame retarding, UPF, the thermal stability and whiteness of polyester fabric; whereas air plasma-nano Ag treatment affects positively the antibacterial activity of the fibre and air plasma-nano $\mathrm{TiO}_{2}$ enhances the fibre protection against ultraviolet rays. The colouration behaviour of the treated samples is unchanged or slightly improved.
\end{abstract}

Keywords: Polyester, Plasma, Nanotechnology, Modification, Dyeing-Printing, UV Protection, Fire Proof, Antibacterial Activity

\section{Introduction}

Plasma, especially glow plasma, is efficient at creating a high density of free radicals by dissociating the molecules through electron collisions and photochemical processes. The gas-phase radicals have sufficient energy to disrupt the chemical bonds in the polymer surface on exposure, which results in the formation of new chemical species. Modification of textile surfaces by plasma technology can be used to obtain nano-porous structures [1]. The plasma coating is more durable than the traditional sprayed finishes because the coating is chemically bonded to the treated fabric [2]. One of the typical plasma discharges operating at atmospheric pressure is the dielectric barrier discharge (DBD). The main characteristic of DBD device is the presence of a dielectric layer within the discharge gap $(0.1-1 \mathrm{~mm})$ insulating at least one of the electrodes [1]. The presence of the dielectric layer characterizes DBD over other types of plasma. Formation of sheath at plasma-dielectric interface is due to the deposition of charges on the dielectric layer which leads to bulk formation of plasma instead of the spark of arc channels. The presence of dielectric layer causes a wide range of frequency which gives DBD its capacitive reactance and hence the formation of displacement current. Plasma in DBD is cold because of the presence of dielectric layer which limits the ohmic (heating) current in the circuit while the displacement current doesn't have any heating effects.

The manufacture of high value-added products such as smart, medical and protective textiles has increased rapidly. The approach to deposit nano-scaled coatings on textiles for sensing monitoring body functions, delivering communication facilities, data transfer, individual environment control and many other applications is studied. Nano materials are fundamentally different from normal 
materials because the surface area of nano particles increases with decreasing the particle size and the behaviour of matter becomes more reliant upon quantum effects [3-8]. The demand for textile flame retardancy is mainly in work clothing, firefighter apparel, upholstery, carpet and military garments. Coating of textiles with fire resistant powder such as $\mathrm{Al}_{2} \mathrm{O}_{3}$ and $\mathrm{Mg}(\mathrm{OH})_{2}$ was tried to get fire resistant fabric $[9,10]$. Another interesting approach is the coating of textiles with nano-particles of titanium dioxide. Metallic silver is an increasingly important material in many technologies. Highly dispersed silver NPs are used as antimicrobial materials [11].

In this work, DBD air plasma was applied to deposit aluminum oxide, nano titanium dioxide and nano silver onto the polyester fabric surface to attain a new approach for producing high added value polyester fabrics that provide consumers with greater levels of functional performance. The work is investigated through evaluation of fibre whiteness, wettability, surface morphology, flame retarding, UPF, antibacterial activity and dyeability as well as printability and fastness properties.

\section{Experimental}

\subsection{Materials}

Polyester fabric (78 dtex, 34 filaments) was provided by Misr Rayon Co., Kafr El-Dawar, Egypt. The fabric was soaped at $40^{\circ} \mathrm{C}$ for $30 \mathrm{~min}$, thoroughly washed, and air dried at room temperature.

Aluminum oxide of particle size $100-200 \mathrm{~nm}$ and NPs of titanium dioxide and silver (particle size $<100$ $\mathrm{nm}$ ) were supplied from Aldrich. All other chemicals used were of reagent grade.

Commercial disperse dyes such as C. I. Disperse Blue 56 and Disperse Red Palanil Rot BF 200\% supplied from BASF were used for dyeing and printing respectively.

\subsection{Methods}

\subsubsection{Fabric Treatment}

The polyester fabric was exposed to low temperature plasma using dielectric barrier discharge (DBD) in atmospheric air at discharge power of 1.3 watt for different time intervals (2 - $10 \mathrm{~min})$. The simplified drawing of the plasma apparatus and list of the device characteristics, such as power input, operating voltage and frequency, gas flow rates and ambient temperature is described elsewhere [12]. The discharge voltage is $9 \mathrm{kV}$ (0 to peak), the discharge current is $1 \mathrm{~mA}$ ( 0 to peak) and the discharge power is $1.3 \mathrm{~W}$. In DBD the discharge power cannot be expressed in the simple form of DC power dissipation; $(\mathrm{W}=\mathrm{IV})$. AC is used where the phase angle between the voltage and current makes that simple ex- pression of power is wrong. The discharge current in DBD has two parts; the real part (ohimc current) and the imaginary part (displacement current). The dissipated power comes only for the real part (ohmic current), while the displacement current doesn't make any dissipation of power. To calculate the discharge power in such cases Lissajous technique is used where a charge voltage diagram is measured and the integration of such diagram is used to measure the power:

$$
\mathrm{W}=\operatorname{Int}(\mathrm{V} \mathrm{dq}) / \mathrm{T}
$$

where Int is the integration over one cycle, dq is the differentiation element of the charge and $\mathrm{T}$ is the periodic time [1].

Aluminum oxide, nano titanium dioxide and nano silver powders $(1 \mathrm{~g} / 100 \mathrm{~g}$ fibre $)$ were distributed carefully either on the polyester samples or on the electrode disk before subjecting to the plasma treatment. In other experiment, some samples were padded in a solution containing $1 \%$ (owf) of nano-silver, squeezed to pick up $100 \%$, air dried and then subjected to air low temperature plasma treatments at discharge powers of 1.3 and 2 watt for 1 and $2 \mathrm{~min}$. The treated samples were washed several times with soap solution containing $1 \mathrm{~g} / \mathrm{l}$ non ionic detergent at $40^{\circ} \mathrm{C}$ for $15 \mathrm{~min}$, rinsed thoroughly with water and then air dried.

\subsubsection{Dyeing Procedure}

Polyester fabrics under investigation were dyed according to the exhaustion technique using $1 \%$ (owf) C. I. Disperse Blue 56. A material to liquor ratio 1:50 was employed and dyeing was allowed to proceed at $\sim 100^{\circ} \mathrm{C}$ for $30 \mathrm{~min}$. The acidity of the dye bath was adjusted to $\mathrm{pH}$ 4.5 with acetic acid. The samples were withdrawn after dyeing, washed and rinsed with water then dried at ambient conditions.

\subsubsection{Printing Technique}

The untreated and treated polyester fabric were printed using conventional silk screen printing technique (manual blade system, three strokes were used). After air drying, the samples were steam fixed for 2 min at $190^{\circ} \mathrm{C}$, then washed according to the following steps:

- Rinsing with cold water.

- Washing with $1 \mathrm{~g} / \mathrm{l}$ nonionic detergent (Aspicon1030) at $40^{\circ} \mathrm{C}$.

- Reductive washing of the dyed samples was normally performed using a solution containing $0.5 \mathrm{~g} / \mathrm{L}$ soda ash, $2 \mathrm{~g} / \mathrm{L}$ sodium hydrosulphite, and $1 \mathrm{~g} / \mathrm{L}$ of a stable surfactant for $15 \mathrm{~min}$ at $70^{\circ} \mathrm{C}$ to ensure the removal of extra dye physically adhered on the fiber surface.

- Rinsing with water at $50^{\circ} \mathrm{C}$.

- Rinsing with cold water and air dried. 


\subsection{Measurements}

\subsubsection{Whiteness}

Changes in fabric whiteness index after treatment were measured using Ultra Scan PRO-Hunter Lab spectrophotometer according to AATCC test method 153-1985 [13].

\subsubsection{Wettability}

The wettability was evaluated by measuring the wetting time according to the AATCC method 35-1989 [14]. The average value of twenty readings was taken as a result.

\subsubsection{Surface Roughness}

Changes in surface roughness values were measured for treated and untreated polyester samples. The Surfacorder Surface Roughness Measuring Instrument SE $1700 \alpha$ (Japan) is used. The results were the average values of ten readings.

\subsubsection{Scan Electron Microscopy (SEM)}

The surface morphology of untreated and treated fabric was investigated by using SEM, JSMT-20, JEOL-Japan. Before examination, the fabric surface was prepared on an appropriate disk and coated randomly by a spray of gold. SEM was carried out in National Research Centre (Egypt).

\subsubsection{Tensile Properties}

Fabric tensile strength test was conducted according to ASTM method 1682 (1994), which is standard method for breaking force and elongation of tensile fabrics [15]. The width and the length of the fabric strip are 5 and 20 $\mathrm{cm}$ respectively. The average of five samples readings is considered.

\subsubsection{Thermo-Gravimetric Analysis}

Thermo-gravimetric analysis (TGA) was carried out using thermal Analyzer 7 Series (Perkin Elmer, USA), with attached TG unit. The sample holder was heated under normal atmosphere at a rate of $10{ }^{\circ} \mathrm{C} / \mathrm{min}$, sensitivity + 25 , chart speed $+5 \mathrm{~mm} / \mathrm{min}$, and the loss in weights of the samples were recorded against temperature from $5^{\circ} \mathrm{C}$ to $500^{\circ} \mathrm{C}[16]$.

\subsubsection{Flame Retardancy}

Determination of burning behaviour of interior materials with a small flame was carried out using the test method ISO 3795-1989. The flame height of $3.8 \mathrm{~cm}$ was applied for a period of $15 \mathrm{sec}$. The time of burning $(\mathrm{sec})$ and the burning rate $(\mathrm{mm} / \mathrm{min})$ were estimated.

\subsubsection{Antibacterial Activity}

Antibacterial activity was carried out by the diffusion disc method [17]. Polyester sample was placed in a Petri dish containing solid bacteria medium (nutrient agar) or fungal medium (Doxs medium) which has been heavily seeded with the spore suspension of the tested organism. The incubation period of the tested microorganism is 24 hours. The tested microorganisms are Staphylococcus aureus $(\mathrm{G}+\mathrm{ve})$, Escherichia coli (G-ve) and Pseudomonas aeruginosa $(\mathrm{G}-\mathrm{ve})$. The diameter of the clear zone of inhibition surrounding the sample was taken as a measure of the fabric activity against the particular test organism. An average value of four measurements was evaluated.

\subsubsection{Ultraviolet Protection Factor (UPF)}

The UPF of untreated and treated PET was measured using Lambda $35 \mathrm{UV} / \mathrm{Vis}$ Systems Spectrophotometer (PerkinElmer, USA, 2001). The protection is evaluated by good, very good and excellent if the values of UPF are $15-24,25-39$ and $>40$ respectively.

\subsubsection{Colour Measurements}

The colour intensity, expressed as K/S value of the dyed and printed polyester samples was determined using Ultra Scan PRO-Hunter Lab spectrophotometer and was estimated by applying the Kubelka-Munk equation [18]. The K/S value of each sample was measured five times and the average result was recorded.

\subsubsection{Fastness Properties}

The dyed samples were washed using $2 \mathrm{~g} / \mathrm{l}$ nonionic detergent (Egyptol PLM) at $40^{\circ} \mathrm{C}$ for $30 \mathrm{~min}$, and tested against washing color fastness properties using the standard test method ISO 105-C04 (1989) [19].

\section{Results and Discussion}

\subsection{Treatment of PET with Plasma- $\mathrm{Al}_{2} \mathrm{O}_{3}$}

Scan Electron Microscopy (SEM): The SEM images were observed to comprehend the alteration of surface morphology of the untreated and plasma- $\mathrm{Al}_{2} \mathrm{O}_{3}$ treated polyester fabrics as shown in Figures 1(a)-(e). Figure 1(a) clearly demonstrates that the untreated polyester fibre had a smooth surface and was free from roughness. Since the smooth outer surface of polyester would not enhance the absorption of moisture, thus the moisture content of the untreated polyester fabric was generally poor. However, Figure 1(b) shows the graph of treated PET with air plasma while Figures 1(c)-(e) show that the SEM graphs of polyester fabric treated with air plasma$\mathrm{Al}_{2} \mathrm{O}_{3}$. It could be seen that there is a drastic change in the fibre surface morphology with the presence of some cracks and deposited $\mathrm{Al}_{2} \mathrm{O}_{3}$ particles which inserted into the pores resulted from the air plasma treatment. Figure 1(c) represents SEM graph of treated polyester sample with plasma- $\mathrm{Al}_{2} \mathrm{O}_{3}$ by distributing the powder either on the sample or on the electrode disk (before washing) 


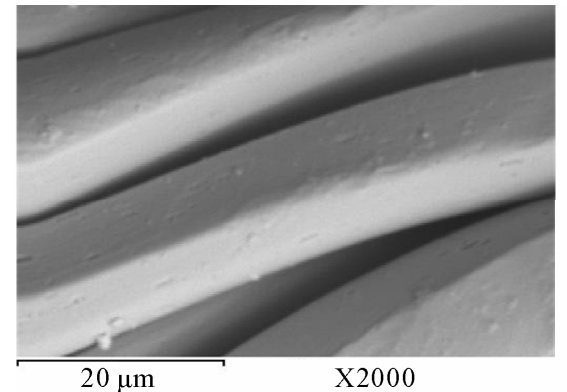

(a)

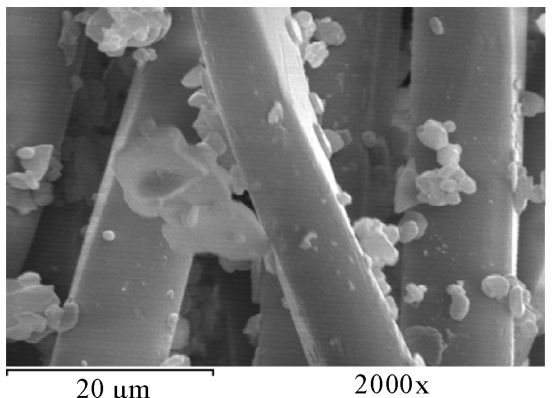

on sample

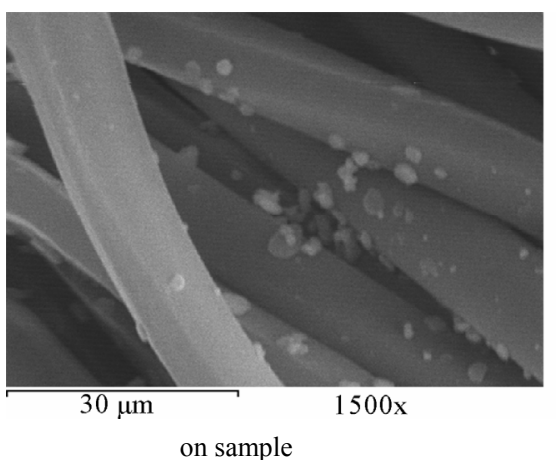

(d)

(c)

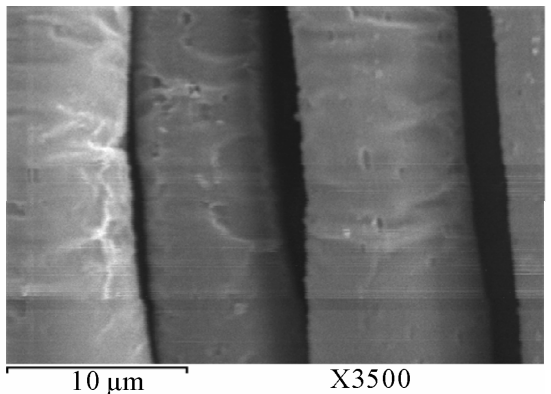

(b)

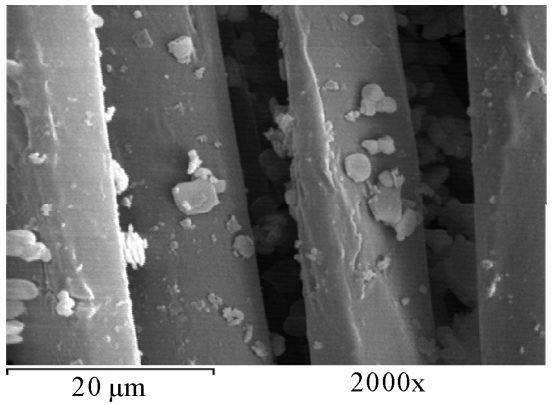

on electrode disk

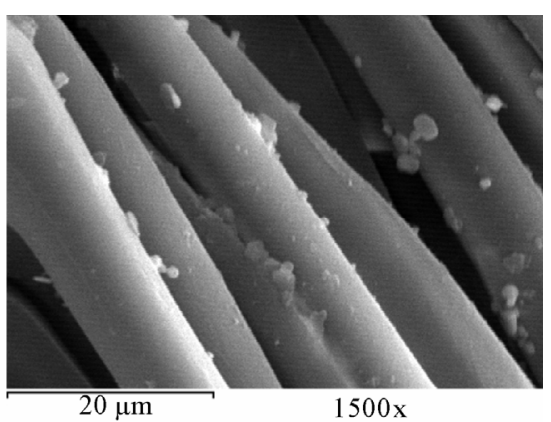

on electrode disk

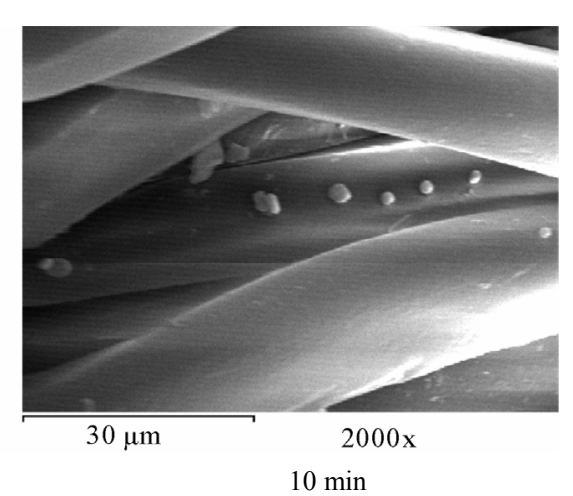

(e)

Figure 1. (a) SEM of untreated PET fabric; (b) SEM of air plasma treated PET at 1.3 watt for 2 min; (c) SEM of air plasma- $\mathrm{Al}_{2} \mathrm{O}_{3}$ treated PET at 1.3 watt for 2 min (before washing); (d) SEM of air plasma- $\mathrm{Al}_{2} \mathrm{O}_{3}$ treated PET at 1.3 watt for 2 min (after washing); (e) SEM of air plasma- $\mathrm{Al}_{2} \mathrm{O}_{3}$ treated PET on sample at 1.3 watt for 5 and 10 min (after washing). 
while Figure 1(d) represents the same samples after washing for about 20 times. It is clear that spreading of $\mathrm{Al}_{2} \mathrm{O}_{3}$ powder on the sample before subjecting to air plasma treatment is more effective on depositing $\mathrm{Al}_{2} \mathrm{O}_{3}$ particles onto polyester fabric than spreading it on the electrode disk. After washing 20 times $\mathrm{Al}_{2} \mathrm{O}_{3}$ particles still exist on the fibre surface but its amount was decreased. It is also noticed from Figures 1(d) and (e) that increasing the plasma exposure time from 2 to $10 \mathrm{~min}$ is not effective on dipping the metal oxide particles. Generally, low temperature plasma treatment did impart a significant alteration to the fibre surface as a result of its etching action on the fibre surface causing surface roughness [10] while presence of $\mathrm{Al}_{2} \mathrm{O}_{3}$ particles on fibre surface affect positively on the flame retardancy, whiteness index and thermal stability as will be discussed later.

Surface Roughness: The surface roughness of untreated and plasma- $\mathrm{Al}_{2} \mathrm{O}_{3}$ treated PET fabric at discharge power of 1.3 watt for different time intervals $(2-10 \mathrm{~min})$ are measured. The results are represented in Table 1. The surface roughness is found to be time dependent and increases gradually with increasing the time of plasma treatment. The surface roughness values are 15.7, 16.7 and $20.2 \mu \mathrm{m}$ for samples treated at 1.3 watt for 2,5 and 10 min respectively (Table 1 ). On the other hand, spreading the $\mathrm{Al}_{2} \mathrm{O}_{3}$ powder on the sample gives higher effect and it is the preferred treatment technique. The surface roughness is due to etching effect of air plasma treatment [20]. Also, addition of nano-particles to the fibre will affect the roughness properties with additional incorporation of the functional properties of nano-particles [21].

Wettability: The primary parameter that characterizes wettability of a surface is the static contact angle, which is defined as the measurable angle that a liquid makes with a surface. The contact angle depends on several factors, such as roughness and the manner of surface preparation and its cleanliness. If the liquid wets the surface and the value of static contact angle is $<90^{\circ}$, it is referred to as hydrophilic surface. Whereas if the liquid does not wet the surface and the value of contact angle is $>90^{\circ}$ and $<180^{\circ}$, it is referred to as hydrophobic surface. All treated fabric with plasma- $\mathrm{Al}_{2} \mathrm{O}_{3}$ either by spreading the powder on sample or on the electrode disk do not wet the fabric and the photo of water drop is shown in Figure 2. It is clear that the contact angle is obtuse angle $\left(>90^{\circ}\right)$ meaning that the plasma- $\mathrm{Al}_{2} \mathrm{O}_{3}$ treated fabric surface

Table 1. Wettability and surface roughness of treated polyester fabric.

\begin{tabular}{cccc}
\hline \multicolumn{2}{c}{ Polyester Sample } & Wettability $(\mathrm{sec})$ & Roughness $(\mu \mathrm{m})$ \\
\hline Untreated & & 11.5 & 14.4 \\
Treated with plasma- $\mathrm{Al}_{2} \mathrm{O}_{3}$ (on sample) for: & $2 \mathrm{~min}$ & $>3600$ & 15.7 \\
& $5 \mathrm{~min}$ & - & 16.7 \\
& $10 \mathrm{~min}$ & - & 20.2 \\
Treated with plasma- $\mathrm{Al}_{2} \mathrm{O}_{3}$ (on disk) for $10 \mathrm{~min}$ & - & 17.4 \\
\hline
\end{tabular}
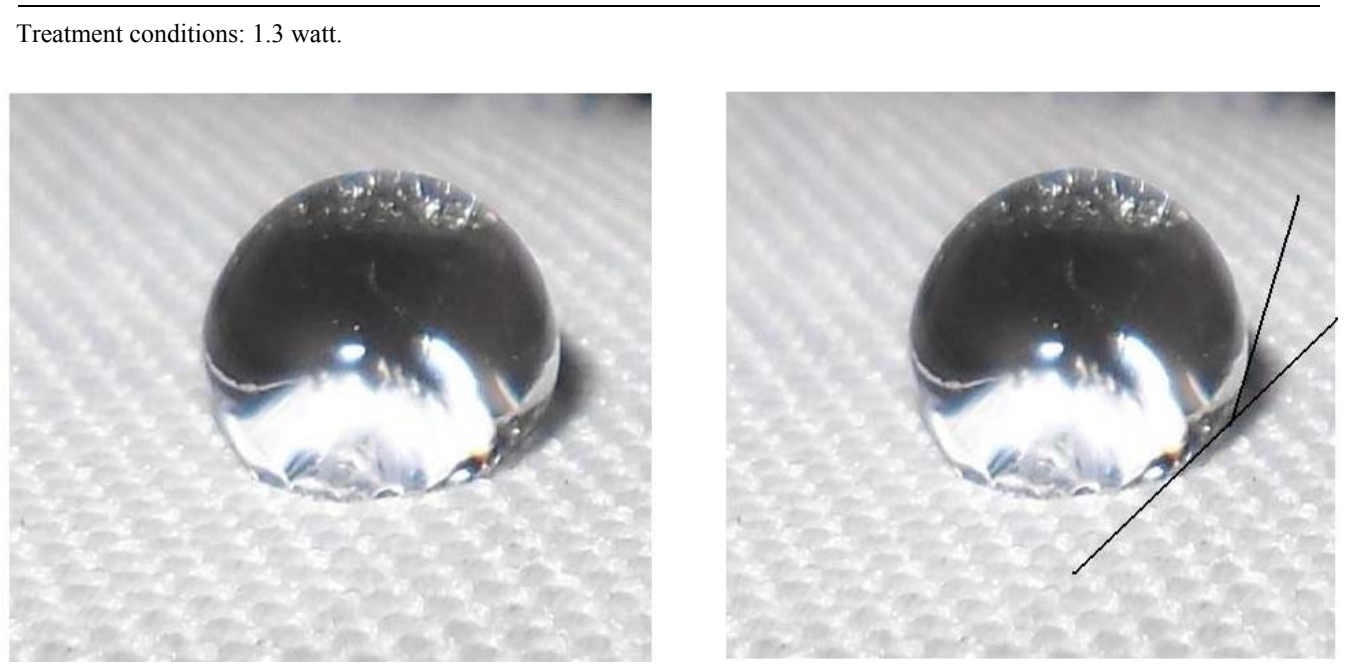

Figure 2. Water drop photo of plasma- $\mathrm{Al}_{2} \mathrm{O}_{3}$ treated PET at 1.3 watt for 2 min. 
becomes more hydrophobic and water repellent. The wetting time as another method for determining the wettability [14] was found to be $>3600 \mathrm{sec}$ for treated samples compared to $11.5 \mathrm{sec}$ for untreated one (Table 1).

The Whiteness Index (WI) for both untreated and treated polyester fabric with air plasma- $\mathrm{Al}_{2} \mathrm{O}_{3}$ was measured. The results are illustrated in Table 2 . It is noticed that this treatment led to a slight increase in whiteness of polyester fabric whereas the WI is found to be 112 for untreated one compared to 116 and 115 for treated samples at 1.3 watt for 2 and 5 min respectively. The maximum \% increase in whiteness $(\sim 4 \%)$ was attained upon treatment with air plasma- $\mathrm{Al}_{2} \mathrm{O}_{3}$ (on sample) at 1.3 watt for $2 \mathrm{~min}$. This slight increase in whiteness index may be due to the combined treatment of plasma and $\mathrm{Al}_{2} \mathrm{O}_{3}$ as reported elsewhere [22] that treatment of textiles with aluminum led to increasing the whiteness and plasma also led to increase the fabric whiteness $[1,8,12]$. Also, it was reported that treatment with $\mathrm{Al}_{2} \mathrm{O}_{3}$ build up a group of metal oxides that have very interesting properties due to the special characteristics such as optical transparency, special dielectric properties and nonlinear optical effects [7]. Increasing the exposure time up to $10 \mathrm{~min}$ led to a decrease in WI to about 108 for samples treated with plasma- $\mathrm{Al}_{2} \mathrm{O}_{3}$ at 1.3 watt (either on sample or on electrode). This decrease in WI may be due to increasing the surface roughness as will be shown later. It was also noticed that the yellowness index (YI) is inversely proportional to the whiteness index.

Ultraviolet Protection Factor (UPF) of untreated and air plasma- $\mathrm{Al}_{2} \mathrm{O}_{3}$ treated PET was measured. The protection is evaluated by good, very good and excellent if the values of UPF are $15-24,25-39$ and $>40$ respectively. It could be shown from Table 2 that the UPF of PET increases from 8 for untreated one to 16 (good protection), 15 (good protection) and 14 for plasma- $\mathrm{Al}_{2} \mathrm{O}_{3}$ treated samples at 1.3 watt for 2,5 and 10 min respectively. It could also be noticed that increasing the expo- sure time is not effective on enhancing the UV protection.

Thermo-Gravimetric Analysis (TGA) of the untreated polyester fabric and treated sample with plasma$\mathrm{Al}_{2} \mathrm{O}_{3}$ (on sample) at 1.3 watt for 2 min were studied. The start and the end of degradation temperatures, peak temperature as well as the corresponding loss in weight of both untreated and treated polyester fabric are given in Table 3. These values indicate that the thermal stability of the treated polyester fabric may increase due to the increase in start and end of degradation temperatures accompanied by a slight decrease in the corresponding loss in weight. The plasma- $\mathrm{Al}_{2} \mathrm{O}_{3}$ treatment caused a significant change in thermal behavior of polyester fabric. The increase in thermal stability of treated sample may reflect on enhancing the flame retardancy of polyester fabric as will be shown later.

Flame Retardancy: Table 4 shows the flammability of plasma- $\mathrm{Al}_{2} \mathrm{O}_{3}$ treated polyester fabric. It can be seen that both the burning time and burning rate are influenced by this treatment. The burning time increases from $39 \mathrm{sec}$ for untreated sample to $50 \mathrm{sec}$ for sample treated with air plasma- $\mathrm{Al}_{2} \mathrm{O}_{3}$ (on sample) at 1.3 watt for 2 min while the burning rate decreases from $230 \mathrm{~mm} / \mathrm{min}$ to $180 \mathrm{~mm} / \mathrm{min}$ for the same samples. These results reflect on enhancing the flame retardancy of polyester fabric. It could be also seen that spreading the powder on sample is more effective on enhancing the fire retarding property than spreading it on the electrode disk. This may be because of the metal hydroxides tending to be endothermic water-releasing systems as reported elsewhere [23]. These results hold true with the TGA results whereas the start and end of degradation temperatures are found to be increased meaning that the thermal stability of PET fabric has increased.

It could be concluded from the previous results that air plasma treatment at 1.3 watt for 2 min after spreading $\mathrm{Al}_{2} \mathrm{O}_{3}$ powder on sample gives the highest effect on en-

Table 2. Whiteness index (W. I.), yellowness index (Y. I.) and UPF of treated polyester fabric.

\begin{tabular}{|c|c|c|c|c|c|}
\hline \multicolumn{2}{|l|}{ Polyester Sample } & Y. I. & W. I. & Change in WI (\%) & UPF \\
\hline \multicolumn{2}{|l|}{ Untreated } & -15.6 & 112.0 & 0 & 8.0 \\
\hline \multirow[t]{3}{*}{ Treated with plasma- $\mathrm{Al}_{2} \mathrm{O}_{3}$ (on sample) for: } & $2 \min$ & -16.4 & 116 & 3.6 & 16.0 \\
\hline & $5 \mathrm{~min}$ & -16.0 & 115 & 2.7 & 15.0 \\
\hline & $10 \mathrm{~min}$ & -13.0 & 108 & -3.6 & 14.0 \\
\hline \multicolumn{2}{|c|}{ Treated with plasma- $\mathrm{Al}_{2} \mathrm{O}_{3}$ (on electrode) for $10 \mathrm{~min}$} & -13.0 & 108 & -3.6 & 8.0 \\
\hline \multicolumn{2}{|l|}{ Treated with plasma- $\mathrm{Ti}_{2}$ for: $2 \mathrm{~min}$} & - & - & - & 48.3 \\
\hline
\end{tabular}

Treatment conditions: 1.3 watt. 
Table 3. TGA of air plasma- $\mathrm{Al}_{2} \mathrm{O}_{3}$ (on sample) treated polyester fabric.

\begin{tabular}{ccccc}
\hline Polyester Sample & Start of Degradation Temperature ${ }^{\circ} \mathrm{C}$ & End of Degradation Temperature ${ }^{\circ} \mathrm{C}$ & Peak Temperature ${ }^{\circ} \mathrm{C}$ & Weight Loss $\%$ \\
\hline Untreated & 291.58 & 430.79 & 395.42 & 83.02 \\
Treated & 320.96 & 438.49 & 407.28 & 80.04 \\
\hline
\end{tabular}

Treatment conditions: 1.3 watt, 2 min.

Table 4. Flammability of air plasma- $\mathrm{Al}_{2} \mathrm{O}_{3}$ treated polyester fabric.

\begin{tabular}{lccc}
\hline \multicolumn{1}{c}{ Polyester Sample } & & Burning Time (sec) & Burning Rate $(\mathrm{mm} / \mathrm{min})$ \\
\hline Untreated & $2 \mathrm{~min}$ & 39 & 230 \\
Treated (on sample) for: & $10 \mathrm{~min}$ & 50 & 180 \\
& $2 \mathrm{~min}$ & 40 & 225 \\
Treated (on disk) for : & $10 \mathrm{~min}$ & 39 & 209 \\
& & 39 & 230 \\
\hline
\end{tabular}

Treatment conditions: 1.3 watt.

hancing UPF and flame retardancy of polyester fabric. So, these optimum conditions are applied on treatment of PET with $\mathrm{TiO}_{2}$ NPs.

\subsection{Treatment of PET with Air Plasma-Nano $\mathrm{TiO}_{2}$}

Polyester fabric was treated with air plasma after spreading of $1 \%$ (owf) of nano $\mathrm{TiO}_{2}(<100 \mathrm{~nm})$ on the sample at 1.3 watt for $2 \mathrm{~min}$. The changes induced in the fibre properties were evaluated through measuring of transmission electron microscopy (TEM) and UPF.

Transmission Electron Microscopy (TEM) of air plasma-nano $\mathrm{TiO}_{2}$ loaded PET fabrics was carried out using JEOL Electron Microscope JEM 1230, JOEL Ltd., Tokyo, Japan. Figure 3(a) shows the TEM graph of plasma- $\mathrm{TiO}_{2}$ treated polyester fiber after washing about 20 times. The size of the $\mathrm{TiO}_{2} \mathrm{NPs}$ ranged from 30 to $90 \mathrm{~nm}$. The spacing between the NPs on the fibers was observed to be irregular. The heterogeneous deposition of the $\mathrm{TiO}_{2}$ on the textiles is probably due to the etching of air plasma and non homogeneous distribution of NPs on the textile surface. $\mathrm{TiO}_{2} \mathrm{NPs}$ have sufficient binding strength with the fibre surface which may be related to the surface modification by plasma such as chemical composition or surface roughness or combination of these effects. It was supposed that $\mathrm{TiO}_{2} \mathrm{NPs}$ formed complexes with oxygen atom built on fibre surface after plasma treatment. $\mathrm{TiO}_{2}$ NPs could be adsorbed on surface with $-\mathrm{COOH}$ groups by forming hydrogen bond or by bounding with two oxygen atoms $[7,8,20]$.

The UPF of air plasma-nano $\mathrm{TiO}_{2}$ treated PET fabric at 1.3 watt for 2 min was found to be 48.3 (>40) which means that the treated fabric has excellent protection against UV radiation (Table 2).

\subsection{Treatment of PET with Air Plasma-Nano Ag}

Polyester fabric was treated with air plasma-nano $\mathrm{Ag}$ via two techniques. The first is by spreading of $1 \%$ (owf) of nano $\mathrm{Ag}(<100 \mathrm{~nm})$ on the sample followed by air plasma treatment at 1.3 watt for $2 \mathrm{~min}$. The second technique is by padding polyester samples in a solution containing $1 \%$ (owf) of the nano-Ag, squeezed to pick up $100 \%$ and air dried, then treated with air plasma at discharge power of 1.3 and 2 watt for 1 and $2 \mathrm{~min}$. All treated samples are washed several times (20 times) in a soap solution at $40^{\circ} \mathrm{C}$ and thoroughly rinsed with water. The effect of this treatment on the fibre properties was evaluated by measuring TEM and antibacterial activity.

TEM of air plasma-nano Ag treated PET fabrics was shown in Figure 3(b). The size of the Ag NPs is less than $100 \mathrm{~nm}$. It could be noticed also that the Ag NPs are dipped perfectly on the fibre surface that reflect positively on fibre durability for antibacterial activity after washing several times.

Antibacterial Activity: Silver was found to be effective in killing over 650 disease-causing microorganisms and it is active against gram-negative bacteria such as Pseudomonas aeruginosa. Based on this hypothesis, Figure 4 shows the photos of inhibition zone of both treated (a) and untreated (b) polyester samples. As the diameter of the clear zone of inhibition increases, the antibacterial activity of the fibre increases. Table 5 represents the values of inhibition zone diameters $(\mathrm{mm})$ of treated polyester fabric with air plasma-Ag NPs. The 


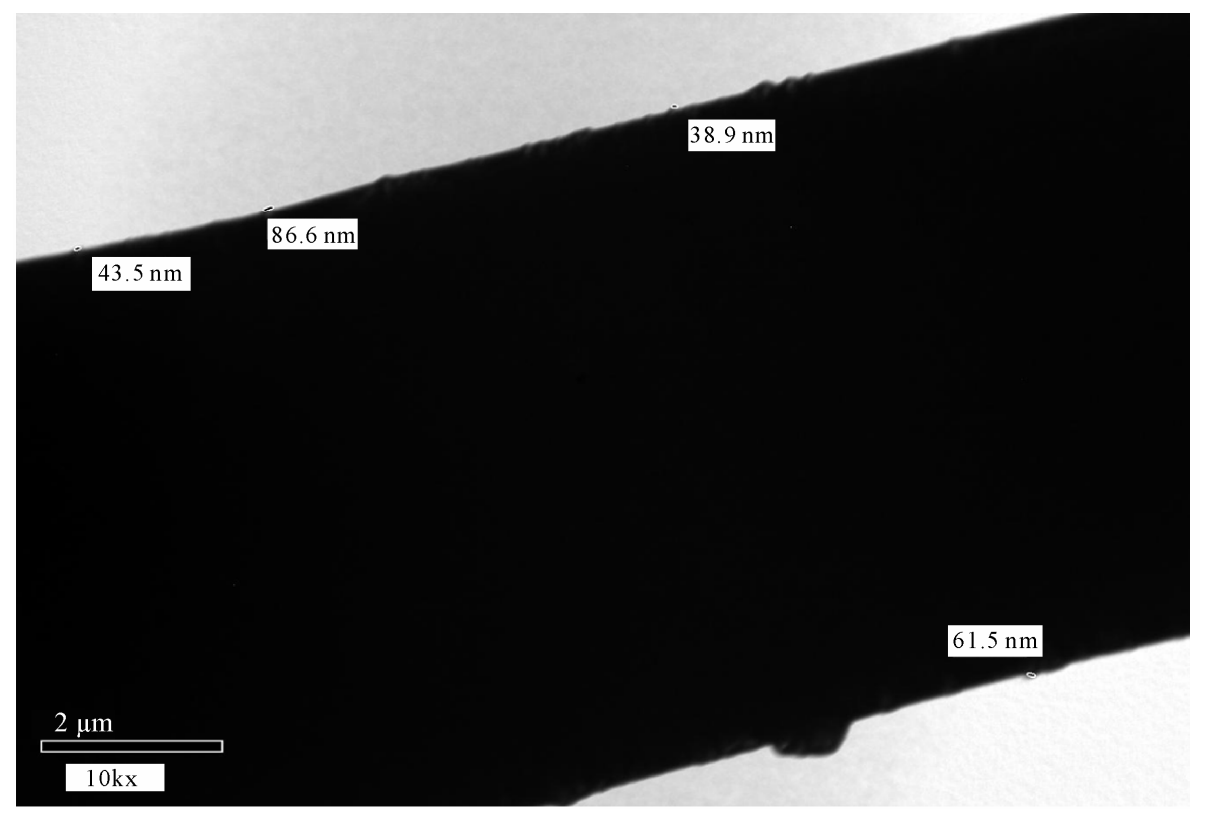

(a)
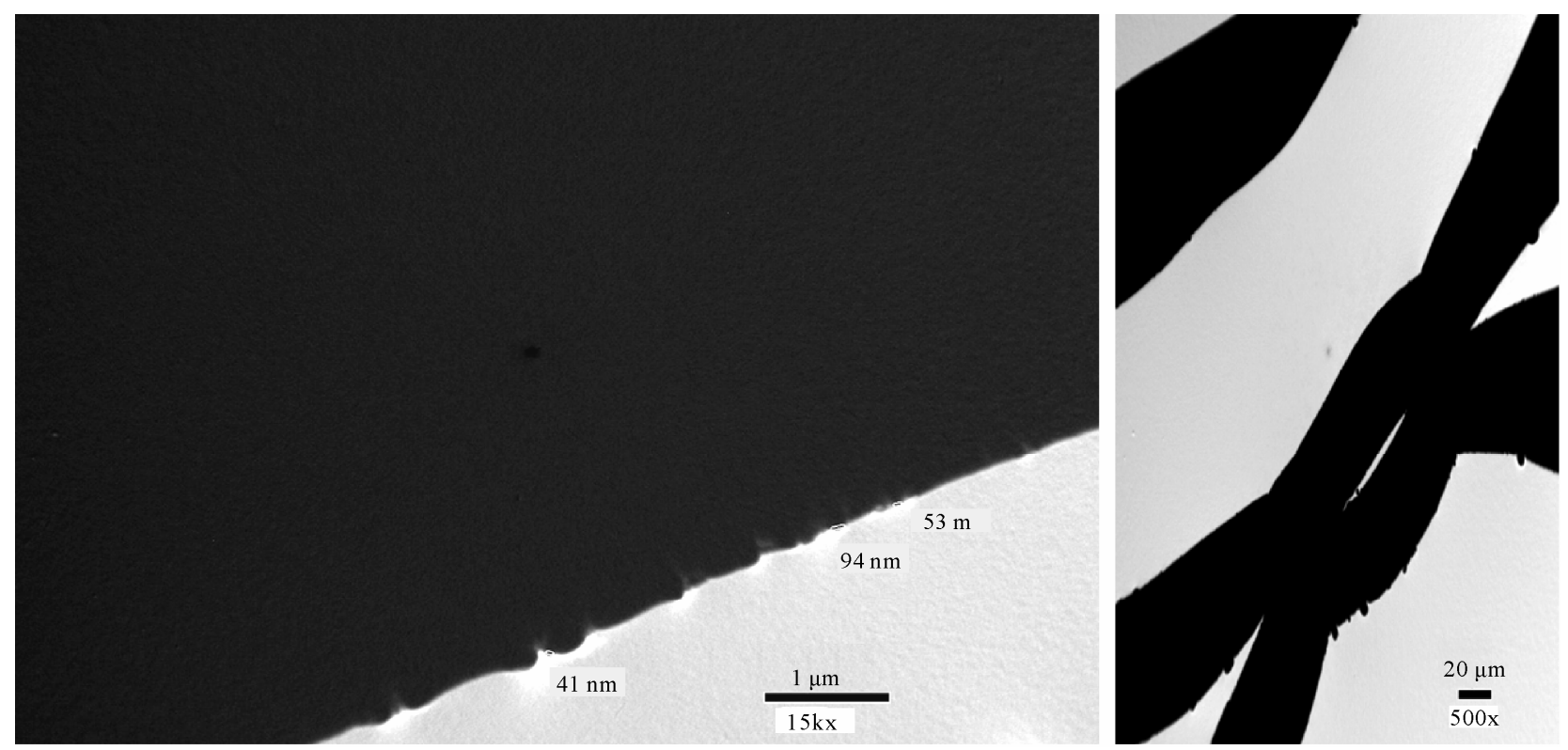

(b)

Figure 3. (a) TEM of air plasma-nano $\mathrm{TiO}_{2}$ treated PET fiber at 1.3 watt for 2 min; (b) TEM of air plasma-nano Ag treated PET fibre at 1.3 watt for $2 \mathrm{~min}$.

antibacterial activity of all treated PET fabrics was improved. The second treatment technique (padding) is found to be more effective on enhancing the antibacterial activity. It is noticed that the maximum inhibition zone could be attained upon using the second technique at discharge power of 1.3 watt for $2 \mathrm{~min}$, while the minimum value was observed for sample treated by the first technique (spreading the NPs on the sample). Three me- chanisms of silver antibacterial effect have been proposed [24]: 1) interference with bacterial electron transport; 2) binding to the bacterial DNA and inactivate it and 3) interaction with cell wall membrane forming reversible complexes on the cell surface and preventing dehydro-oxygenation process.

Tensile Properties: The tensile strength and elongation \% at break of untreated PET sample are $125 \mathrm{~kg}$ and 


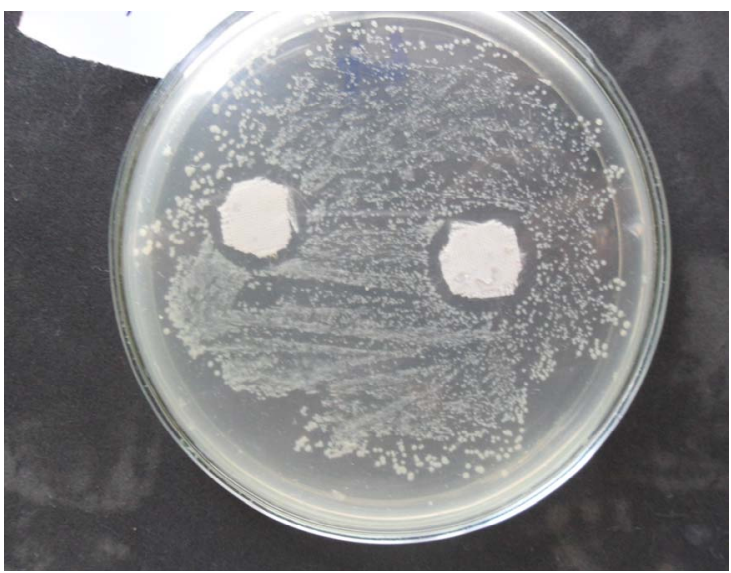

(a)

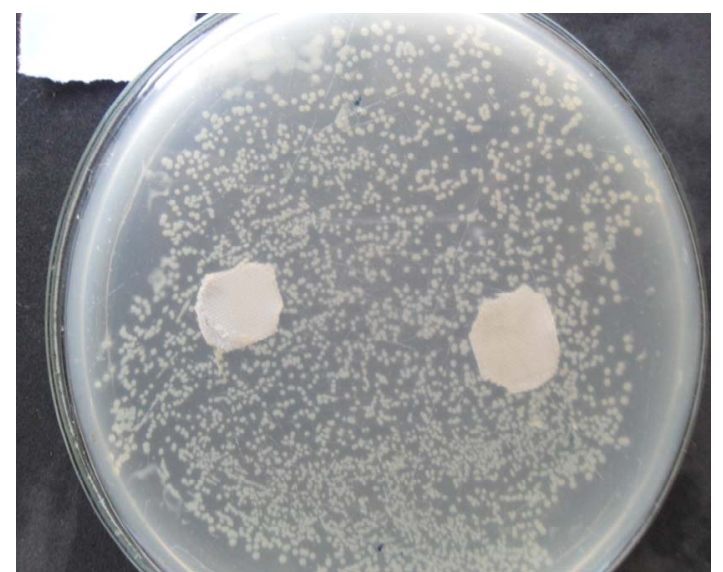

(b)

Figure 4. Photos of inhibition zone of treated (a) and untreated (b) PET samples.

Table 5. Antibacterial properties of air plasma-nano Ag treated polyester fabric.

\begin{tabular}{|c|c|c|c|}
\hline Sample & E-coli (G-ve) & Pseudomonas (G-ve) & Staphylococcus $(\mathrm{G}+\mathrm{ve})$ \\
\hline Untreated & 0 & 0 & 0 \\
\hline Treated at: 1.3 watt, 2 min (on sample) & 11 & 12 & 12 \\
\hline 1.3 watt, 1 min (padding) & 15 & 17 & 16 \\
\hline 1.3 watt, 2 min (padding) & 18 & 20 & 19 \\
\hline 2 watt, 1 min (padding) & 18 & 18 & 18 \\
\hline 2 watt, 2 min (padding) & 18 & 20 & 19 \\
\hline
\end{tabular}

Inhibition zone: - no activity, $+1-5 \mathrm{~mm},++6-9 \mathrm{~mm},+++10-19 \mathrm{~mm},++++20-29 \mathrm{~mm}$.

$50 \%$ respectively compared to $120-125 \mathrm{~kg}$ and $45 \%$ $50 \%$ for treated samples. Therefore, it seems that the plasma impact damage to the fabric is negligible.

Coloration Behavior: Polyester fabrics are dyeable and printable with disperse dyes. The colour intensity $(\mathrm{K} / \mathrm{S})$ of untreated and treated PET fabric with plasma$\mathrm{Al}_{2} \mathrm{O}_{3}$, plasma-nanoTiO ${ }_{2}$ and plasma-nano $\mathrm{Ag}$ at 1.3 watt for $2 \mathrm{~min}$ and dyed at $100^{\circ} \mathrm{C}$ was measured. The results show that the treatment brings out a slight increase in colour intensity compared to the untreated one whereas the highest colour intensity $(\mathrm{K} / \mathrm{S})$ of treated fabric with plasma- $\mathrm{TiO}_{2}$ was found to be 3.7 compared to 3.4 for untreated one (Table 6). Since the dyeability of PET fabric has been related to hydrophilicity and/or increase of micro roughness and surface morphological modification therefore, plasma treatment can increase the diffusion of the dye molecules into the fibre and consequently improves the fibres dyeability $[8,25]$. Also, the printability of treated fabric with plasma- $\mathrm{Al}_{2} \mathrm{O}_{3}$ at 1.3 watt for 2 min was tried. The colour intensity of treated sample increased from 13.4 for untreated sample to 14.2 for treated one. The washing fastness of coloured treated samples is estimated to be 4 or 4 - 5 which almost the same for the untreated one (Table 6).

\section{Conclusions}

The possibility of using atmospheric plasma DBD to facilitate the deposition of $\mathrm{Al}_{2} \mathrm{O}_{3}$, nano silver and nano $\mathrm{TiO}_{2}$ onto polyester fabric was investigated. Multifunctional polyester fabric was produced. It was found that the results depend on the plasma discharge power and exposure time. Treatment of PET with plasma- $\mathrm{Al}_{2} \mathrm{O}_{3}$ indicated that whiteness index and surface roughness were dependent on the time of exposure. The TGA analysis and flame retardancy tests at 1.3 watt for $2 \mathrm{~min}$ indicate that this treatment caused an improvement in thermal stability and flame retardancy which was found to be more effective upon using the technique of spreading the powder on the sample rather than on the electrode disk. UPF was also improved. Plasma-nano $\mathrm{TiO}_{2}$ treatment resulted in a noticeable enhancement in UPF of polyester fabric. Treatment with plasma-nano Ag was evaluated by the measurements of antibacterial activity which was found to be improved. It was also concluded 
Table 6. Colour strength (K/S) of dyed and printed PET fabric.

\begin{tabular}{llccc}
\hline & Sample & $\mathrm{K} / \mathrm{S}$ & \multicolumn{2}{c}{ washing fastness } \\
\cline { 4 - 4 } 1. Dyed PET samples: & & alt & 4 \\
& untreated & 3.4 & $4-5$ & $4-5$ \\
& treated with plasma- $\mathrm{Al}_{2} \mathrm{O}_{3}$ & 3.6 & $4-5$ & $4-5$ \\
& treated with plasma- $\mathrm{TiO}_{2}$ & 3.7 & $4-5$ & $4-5$ \\
& treated with plasma-Ag & 3.6 & 4 & 4 \\
& untreated & 13.4 & 4 & 4 \\
& treated with plasma- $\mathrm{Al}_{2} \mathrm{O}_{3}$ & 14.2 & 4 & 4 \\
\hline
\end{tabular}

Treatment: 1\% (owf), 1.3 watt, 2 min; Dyeing: $1 \%$ (owf) C. I. Disperse Blue 56, $100^{\circ} \mathrm{C}, 30 \mathrm{~min}, \mathrm{pH} 4.5$, liq. ratio 1:50.

that the colourations and fastness behaviour of the treated fabric was slightly improved over the untreated samples.

\section{REFERENCES}

[1] R. Shishoo, "Plasma Technology for Textiles," Chapter 6, Woodhead Publishing Limited, Cambridge, 2007, p. 159.

[2] J. Zhang, P. France, A. Radomyselskiy, S. Datta, J. Zhao and W. Van Ooij, "Hydrophobic Cotton Fabric Coated by a Thin Nanoparticulate Plasma Film," Journal of Applied Polymer Science, Vol. 88, No. 6, 2003, pp. 1473-1481. doi:10.1002/app.11831

[3] G. J. Gabriel, A. Som, A. E. Madkour, T. Eren and G. N. Tew, "Infections Disease: Connecting Innate Immunity to Biocidal Polymers," Materials Science and Engineering: $R$, Vol. 57, No. 1-6, 2007, pp. 28-64. doi:10.1016/j.mser.2007.03.002

[4] L. Qian and J. P. Hinestroza, "Application of Nano-Technology for High Performance Textile," Journal of Textile and Apparel, Technology and Management, Vol. 4, No. 1, 2004, pp. 1-4.

[5] N. Vigneshwaran, S. Kumar, A. A. Kathe, P. V. Vradarajan and V. Prasad, "Functional Finishing of Cotton Fabrics Using Zinc Oxide-Soluble Starch Nano-Composites," Nanotechnology, Vol. 17, No. 20, 2006, pp. 5087-5095. doi:10.1088/0957-4484/17/20/008

[6] H. J. Lee and S. H. Jeong, "Bacteriostasis and Skin Innoxiousnes of Nano-Size Silver Colloids on Textile Fabrics," Textile Research Journal, Vol. 75, No. 7, 2005, pp. 551-556. doi:10.1177/0040517505053952

[7] F. Effenberger, "Application of Nanotechnologies in Textiles," 3rd International Conference of Textile Research Division, Cairo, 2-4 April, 2006, pp. 487-493.

[8] I. Holme, "Innovative Technologies for High Performance Textiles," Coloration Technology, Vol. 123, No. 2, 2007, pp. 59-73. doi:10.1111/j.1478-4408.2007.00064.x

[9] P. R. Hornsby, "The Application of Fire-Retardant Fillers for Use in Textile Barrier Materials," In: S. Duquesne, C. Magniez and G. Camino, Eds., Multifunctional Barriers for Flexible Structures, Springer Series in Materials Sci- ence, Vol. 97, Springer, New York, 2007, pp. 1-22.

[10] S. M. Gawish, A. M. Ramadan, C. E. Cornelius, M. A. Bourham, S. R. Matthews, M. G. McCord, D. M. Wafa and F. Breidt, "New Functionalities of PA6,6 Fabric Modified by Atmospheric Pressure Plasma and Grafted Glycidyl Methacrylate Derivatives," Textile Research Journal, Vol. 77, No. 2, 2007, pp. 92-104. doi: $10.1177 / 0040517507076747$

[11] I. Sondi, D. V. Goia and E. Matijević, "Preparation of Highly Concentrated Stable Dispersions of Uniform Silver Nanoparticles," Journal of Colloid and Interface Science, Vol. 260, No. 1, 2003, pp. 75-81. doi:10.1016/S0021-9797(02)00205-9

[12] E. M. El-Khatib, W. M. Raslan, A. A. El-Halwagy and S. Galab, "A New Approach to Improve Dyeability of Wool/ Polyester Blend Using Low Temperature Plasma Techniques," 3rd Aachen/Dresden Textile Conference, Aachen, 26-27 November 2009.

[13] AATCC, Technical Manual, Test Method, 153, 1985.

[14] AATCC, Technical Manual, Test Method, 35, 1989.

[15] ASTM, Standard Test Method, 1682, 1994.

[16] L. M. O’Reilly and F. E. Karasz, "Special Heat Studies of transition and Relaxation Behavior in Polymers," Journal of Polymer Science Part C, Vol. 14, No. 1, 1966, p. 49.

[17] M. Tsukada, T. Arai, G. M. Colonna, A. Boschi and G. Freddi, "Preparation of Metal-Containing Protein Fibers and Their Antimicrobial Properties," Journal of Applied Polymer Science, Vol. 89, No. 3, 2003, pp. 638-644. doi:10.1002/app.11911

[18] B. D. Judd and G. Wysezecki, "Colour in Business Science and Industry," 3rd Edition, John Wiley and Sons, New York, 1975.

[19] Iso Recommendation Test for Colour Fastness to Textiles, 105-C04, 1989.

[20] J. Yip, "Low Temperature Plasma-Treated Nylon Fabric," Journal of Materials Processing Technology, Vol. 123, No. 1, 2002, pp. 5-12. doi:10.1016/S0924-0136(02)00024-9

[21] S. Gowri, L. Almeida, T. Amorim, N. Carneiro, A. P. 
Souto and M. F. Estves, "Polymer Nano Composites for Multifunctional Finishing of Textiles-A Review," Textile Research Journal, Vol. 80, No. 13, 2010, pp. 1290-1306. doi:10.1177/0040517509357652

[22] A. Bendak, W. M. Raslan and M. Salama, "Treatment of Wool with Metal Salts and Their Effects on Its Properties," Journal of Natural Fibers, Vol. 5, No. 3, 2008, pp. 251-269.

[23] E. D. Weil and S. V. Levchik, "Flame Retardants in Commercial Use or Development for Textiles," Journal of Fire Sciences, Vol. 26, No. 3, 2008, pp. 243-281. doi: $10.1177 / 0734904108089485$
[24] T. Yuranova, A. G. Rincon, A. Bozzi, S. Parra, C. Pulgarin, P. Albers and J. Kiwi, "Antibacterial Textiles Prepared by RF-Plasma and Vacuum-UV Mediated Deposition of Silver," Journal of Photochemistry and Photobiology A: Chemistry, Vol. 161, No. 1, 2003, pp. 27-34. doi:10.1016/S1010-6030(03)00204-1

[25] S. R. Matthews, Y. J. Hwang, M. G. McCord and M. A. Bourham, "Investigation into Etching Mechanism of Polyethylene Terephthalate (PET) Films Treated with Helium and Oxygenated Helium Atmospheric Plasmas," Journal of Applied Polymer Science, Vol. 94, No. 6, 2004, pp. 2383-2389. doi:10.1002/app.21162 